\title{
Change in cigarette dependence among a cohort of smokers following COVID-19 diagnosis in Kashmir valley: An observational follow-up study
}

\author{
Hilal Rather ${ }^{1}$, Shafat Sideeq Lone ${ }^{2}$, Asif Jeelani ${ }^{3}$ \\ ${ }^{1,3}$ Senior Resident, Department of Community Medicine, Government Medical College, ${ }^{2}$ Resident, Department of \\ Internal Medicine, Jawahar Lal Nehru Memorial Hospital, Srinagar, India
}

Background: COVID-19 diagnosis should serve as an impetus for smokers to discontinue its use. The study was conducted to estimate the change in cigarette dependence among newly diagnosed COVID-19 cases. Aims and Objectives: COVID-19 diagnosis should serve as an impetus for smokers to discontinue its use. The study was conducted to estimate change in cigarette dependence among newly diagnosed COVID-19 cases. Materials and Methods: Study was conducted between October and December 2020 and newly diagnosed male COVID-19 patients who were current smokers at diagnosis were recruited from two hospitals involved in testing and treatment of COVID-19. Baseline socioclinical information was recorded at diagnosis in addition to the estimation of cigarette dependence using Fagerstrom Test for Nicotine Dependence (FTND) and health status using Post-COVID-19 Functional Scale (PCFS). Follow-up was done at 2 weeks after recovery using both FTND and PCFS scales. Wilcoxon signed-rank test, paired t-test, and ANOVA were used for univariate analysis and multivariate regression was done. Results: A total of 171 subjects with mean age of 43.79 years were included in the study. FTND scores decreased significantly from the day of diagnosis to follow-up visit with $79 \%$ of subjects reporting a decrease. On univariate analysis, decrease in FTND had a significant association with presence of comorbidity, any symptoms, presence of respiratory symptoms, and if supplemental oxygen was administered. On multivariate analysis, symptomatic COVID-19 disease, higher age, PCFS at baseline, and PCFS at follow-up had a significant association with decreased PCFS values at followup. Conclusion: COVID-19 diagnosis was followed by significant decrease in FTND score, particularly for symptomatic and older subjects. Post-COVID follow-up visits should be used as an opportunity by health providers to ensure its sustainability and for achieving cessation.

\section{Access this article online}

\section{Website:}

http://nepjol.info/index.php/AJMS DOI: 10.3126/ajms.v12i11.39636 E-ISSN: 2091-0576 P-ISSN: 2467-9100

Copyright (c) 2021 Asian Journal of Medical Sciences

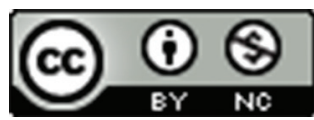

This work is licensed under a Creative Commons Attribution-NonCommercial 4.0 International License.

Key words: COVID-19; Fagerstrom test; Follow-up; Nicotine dependence

\section{INTRODUCTION}

Tobacco use is a major risk factor for non-communicable diseases, particularly cardiovascular and respiratory diseases. ${ }^{1}$ Every year around 8 million people die from its use with low- and middle-income countries facing a disproportionate burden of morbidity and mortality from tobacco use. ${ }^{2,3 \text { Dec }}$ reasing the use of tobacco is an important intervention in the SDGs and multiple interventions were in pipeline globally and nationally to decrease its use. ${ }^{4,5}$ The world was making significant progress toward achieving these goals when the COVID-19 pandemic started and has been throwing up multiple challenges to the global community. ${ }^{6,7}$ One important challenge was the impact the COVID-19 pandemic can have on the use of addictive substances. Multiple studies were conducted which covered two important research areas, one being the impact of COVID-19 and associated lockdowns on smoking pattern 
among non-COVID-19 subjects. ${ }^{8,9}$ The second research area was related to the impact current/past smoking can have on outcome in COVID-19-infected pateints. ${ }^{10,11} \mathrm{~A}$ main finding was that smokers are at higher risk of mortality from COVID-19. Functional status after COVID-19 is an important factor which can determine tobacco use after COVID-19. One of the widely used scales is the PostCOVID-19 Functional Scale (PCFS), which is a validated scale for measuring functional status after COVID-19. ${ }^{12}$ An important area on which there is a very sparse literature is the impact COVID-19 diagnosis can have on nicotine dependence and the correlates which determine the degree and direction of change. Studies estimating the change in cigarette dependence after COVID-19 diagnosis can provide information which can be used in developing smoking cessation interventions in COVID-19 patients. There are multiple validated tests for quantifying nicotine/cigarette dependence. Fagerstrom Test for Nicotine Dependence (FTND) test is one such test that transforms dependence into an ordinal scale and has been validated and used to measure nicotine dependence. . $^{13,14}$

\section{Aims and objectives}

Considering the intricate relationship between smoking and COVID-19 and the fact that a COVID-19 diagnosis can impact the degree of dependence, the present study was conducted to estimate change in nicotine dependence among current smokers after COVID-19 diagnosis using FTND test.

\section{MATERIALS AND METHODS}

\section{Study design and setting}

The study used an observational follow-up design and was conducted at two primary care hospitals in Srinagar district from October to November 2020. This period coincided with the later stages of first wave and was characterized with decreasing number of daily new infection. The daily average new case notification rate locally was 500 per day during the study period whereas around 50,000 cases were being reported per day nationally in the same period. ${ }^{15}$ A total of 60 lakh cases and around 1 lakh deaths were reported nationally till the start of study. ${ }^{16}$ The study area lies in North India and prevalence of tobacco smoking in the area is $35 \%$ in males and $5 \%$ in females as per the latest Global Adult Tobacco Survey. ${ }^{17}$

\section{Participants}

Study participants were incident cases of COVID-19 who were current smokers and were selected from individuals reporting for COVID-19 testing to the health facility. ${ }^{18}$ The subjects were tested as per national guidelines and those who were positive for COVID-19 and current smokers were included. Subjects who had smoked at least 100 cigarettes in their lifetime and were currently smoked were classified as current smokers. ${ }^{19}$ An informed consent was taken after explaining the purpose of the study and subjects who provided consent included in the study. Considering the high degree of social taboo regarding smoking among females in the study area, only males were included in the study which was also supported by the fact that no female COVID-19 patient reported as being current smoker in pretest in comparison to around $1 / 3^{\text {rd }}$ of males.

\section{Demographic and clinical information}

Socioclinical history was recorded using a pretested schedule and recorded information related to demographic characteristics, duration of smoking, and presence of any comorbidities. Socioeconomic status was categorized as per Kuppuswamy scale for 2021. For the purpose of analysis, Classes II and III were clubbed as middle and Classes IV and $\mathrm{V}$ were clubbed as lower socioeconomic status. In addition, peripheral capillary oxygen saturation $\left(\mathrm{SpO}_{2}\right)$ was also recorded at baseline and follow-up.

Assessment of dependence and post-COVID-19 functional status

Dependence to cigarette smoking was assessed using FTND test which was done at baseline and at follow-up visit. The test converts smoking dependence on an ordinal scale with a range of possible scores from 1 to 10 . Higher scores signify higher dependence. Internal consistency of the FTND test was checked at baseline using Cronbach alpha which was 0.71 in the study population, functional status of COVID-19 patients was estimated using PCFS scale. ${ }^{12,20}$ A translated version of the scale which was first pre-tested on 30 recovered COVID-19 patients was used. The subjects first responded to this scale at baseline and then again at follow-up. The scale grades functional disability from 0 to 4 with lower scores implying least functional impairment. ${ }^{21}$ PCFS has been validated in multiple studies and the internal consistency estimated by Cronbach alpha was 0.61 in the study population.

\section{Inclusion criteria}

The following criteria were included in the study:

- Male gender, age 18 years.

- Current smoker.

\section{Exclusion criteria}

The following criteria were excluded from the study:

- Severe disease at baseline.

- $\mathrm{SpO}_{2}<91$ at baseline.

- Cognitive limitation, subject requiring hospital admission due to any cause.

\section{Sample size}

Sample size was calculated using formula $\mathrm{n}=(\mathrm{z} \sigma / \mathrm{E})^{2}$ where $\sigma$ is the standard deviation and $\mathrm{E}$ is desired margin 
of error. Margin of error of 0.25 and $\sigma$ of 1.6 was used, that estimated the same size to be 160 . Standard deviation was estimated from interim analysis of data from the first 50 subjects. A total of 171 subjects were included in the study. Figure 1 describes the selection process for study subjects.

\section{Statistical analysis}

Data were entered into Excel and analyzed using Stata Ver 13. Categorical variables were summarized as proportion and percentages. Quantitative variables were summarized using mean, SD, median, and IQR. Changes in quantitative variable from baseline to follow-up visit were tested for significance using Wilcoxon signed-rank test. Association between variables was estimated by Spearman rank correlation coefficient, t-test, and ANOVA depending on type and number of categories in the variable. Percent change in FTND was calculated and multivariate analysis was used to estimate factors having an independent association with it.

\section{Ethics statement}

The study was approved by the Institutional Review Committee. Only subjects who provided informed consent were included with subjects having an option to opt out at any time.

\section{RESULTS}

A total of 171 male subjects were included with a mean age of $43.79 \pm 13.76$. The sample comprised $85 \%$ literate subjects and $2 / 3^{\text {rd }}$ were married. Around $1 / 3^{\text {rd }}$ subjects had any comorbidity at baseline - with hypertension and diabetes contributing to most of these cases. Around $42 \%$ of subjects had any symptoms of which $88 \%$ had respiratory symptoms. Eighteen $(10.5 \%)$ subjects needed supplemental oxygen over the course of their illness. The sociodemographic profile of study subjects is described in Table 1.

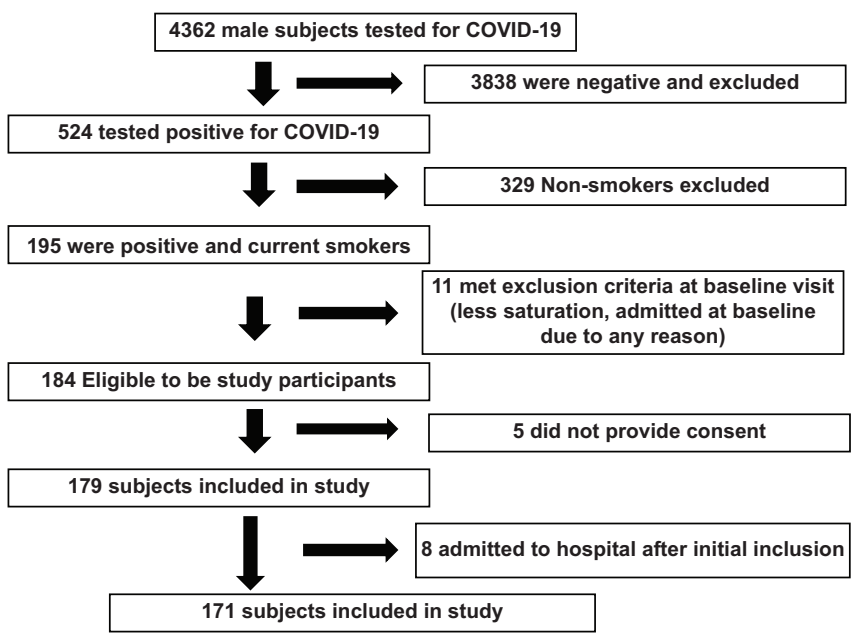

Figure 1: Flowchart of study subjects
Table 2 is depicting the distribution of continuous variables. Mean duration of smoking was 17.16 years. The FTND test had a mean score of 6.15 at baseline and 3.74 at follow-up. The minimum $\mathrm{SpO}_{2}$ at baseline was 92 . The national guidelines mandated hospital admission of COVID-19 patients with saturation below this at baseline. Those subjects were not included as hospital admission was exclusion criteria for the study. The FTND test had a significant decrease at follow-up in comparison to baseline with 135 subjects (79\%) reporting a decreasing in nicotine dependence. PCFS did not have a significant change from baseline to follow-up. The details are provided in Table 3.

Table 4 is depicting the correlation of nicotine dependence at follow-up with continuous variable. The correlation was significant for $\mathrm{SpO}_{2}$ at baseline, $\mathrm{SpO}_{2}$ at follow-up, and PCFS at baseline and follow-up.

Table 5 is depicting the association of categorical variables with change in nicotine dependence. On univariate analysis, age, education, socioeconomic status, presence

\begin{tabular}{|c|c|c|}
\hline Variable & $\mathbf{N}$ & $\%$ \\
\hline \multicolumn{3}{|l|}{ Age mean $\pm S D$} \\
\hline $43.79 \pm 13.76$ & 171 & $100 \%$ \\
\hline \multicolumn{3}{|l|}{ Age group (years) } \\
\hline$<35$ years & 45 & 26.32 \\
\hline $36-49$ years & 54 & 31.58 \\
\hline$>50$ & 72 & 42.11 \\
\hline \multicolumn{3}{|l|}{ Education } \\
\hline Uneducated & 27 & 15.79 \\
\hline Primary & 81 & 47.37 \\
\hline Secondary and above & 63 & 36.84 \\
\hline \multicolumn{3}{|l|}{ Socioeconomic status ${ }^{8}$} \\
\hline Low & 45 & 26.32 \\
\hline Middle & 81 & 47.37 \\
\hline High & 45 & 26.32 \\
\hline \multicolumn{3}{|l|}{ Marital status } \\
\hline Single & 45 & 26.32 \\
\hline Married & 126 & 73.68 \\
\hline \multicolumn{3}{|l|}{ Hypertension/diabetes } \\
\hline Yes & 54 & 31.58 \\
\hline No & 117 & 68.42 \\
\hline \multicolumn{3}{|c|}{ Chronic respiratory disease } \\
\hline Yes & 4 & 2.34 \\
\hline No & 167 & 97.66 \\
\hline \multicolumn{3}{|l|}{ Cigarette use at home } \\
\hline Yes & 72 & 42.11 \\
\hline No & 99 & 57.89 \\
\hline \multicolumn{3}{|l|}{ Symptoms } \\
\hline Yes & 72 & 42.11 \\
\hline No & 99 & 57.89 \\
\hline \multicolumn{3}{|l|}{ Respiratory symptoms } \\
\hline Yes & 63 & 36.84 \\
\hline No & 108 & 63.16 \\
\hline \multicolumn{3}{|l|}{ Supplementary oxygen } \\
\hline Yes & 18 & 10.53 \\
\hline No & 153 & 89.47 \\
\hline
\end{tabular}


of comorbidity, presence of symptoms, and need for supplemental oxygen were significantly associated with percent change in nicotine dependence.

Table 6 is depicting the results of multivariate analysis of selected variable which was significant on univariate analysis. Percent change in FTND scores was used as a dependent variable.

\section{DISCUSSION}

This study planned to estimate the impact of COVID-19 on change in nicotine dependence among newly diagnosed

\begin{tabular}{|c|c|c|c|c|c|c|}
\hline & Mean & SD & Min. & Median & Max. & IQR \\
\hline Age & 43.79 & 13.76 & 20 & 46 & 65 & 24 \\
\hline $\begin{array}{l}\text { Smoking } \\
\text { duration }\end{array}$ & 17.16 & 10.36 & 1 & 46 & 32 & 24 \\
\hline $\begin{array}{l}\text { Spo2 } \\
\text { (baseline) }\end{array}$ & 95.58 & 1.9 & 92 & 96 & 99 & 3 \\
\hline $\begin{array}{l}\mathrm{SpO}_{2} \\
\text { (follow-up) }\end{array}$ & 95.37 & 2.41 & 89 & 96 & 99 & 2 \\
\hline $\begin{array}{l}\text { FTND } \\
\text { (baseline) }\end{array}$ & 6.15 & 1.53 & 2 & 7 & 8 & 1 \\
\hline $\begin{array}{l}\text { FTND } \\
\text { (follow-up) }\end{array}$ & 3.74 & 1.55 & 0 & 4 & 6 & 2 \\
\hline $\begin{array}{l}\text { PCFS } \\
\text { (baseline) }\end{array}$ & 0.68 & 0.8 & 0 & 0 & 2 & 1 \\
\hline $\begin{array}{l}\text { PCFS } \\
\text { (follow-up) }\end{array}$ & 0.947 & 1.36 & 0 & 0 & 4 & 2 \\
\hline
\end{tabular}

\begin{tabular}{lc} 
Table 3: Change in FTND test and PCFS scores \\
from initial to follow-up visit \\
\hline $\begin{array}{l}\text { Change in FTND scores from initial to follow-up } \\
\text { visit }\end{array}$ & $\mathbf{N}$ \\
\hline Follow-up FTND score<baseline score & 135 \\
Follow-up FTND score>baseline score & 18 \\
Ties & 18 \\
$Z=-10.117 ;$ P=0.001 & $\mathbf{N}$ \\
\hline Change in Post-COVID-19 Functional Scale scores \\
from initial to follow-up visit \\
\hline Follow-up PCFS score<baseline score \\
Follow-up PCFS score>baseline score \\
Ties \\
$Z=2.075 ; P=0.0380$ \\
Wilcoxon signed rank test \\
\hline FTND: Fagerstrom Test for Nicotine Dependence, PCFS: Post-COVID-19 Functional Scale
\end{tabular}

COVID-19 male patients. To the best of our knowledge, this is one of the first studies that estimated change in smoking dependence after COVID-19 infection. The study can provide inputs in designing a tailored behavior change communication strategy which can be delivered to recovered COVID-19 patients during routine followup visits. ${ }^{22}$

Data indicated that 135 subjects (79\% subjects) had a decreased FTND test scores when compared to their respective scores at baseline. Overall, there was a significant decrease in nicotine dependence among the study subjects. Multiple regression analysis indicated that being married, older age, decreased saturation at follow-up visit, presence of any comorbidity, presence of respiratory symptoms, and need for supplementary oxygen during the course of illness were significantly associated with a decrease in nicotine dependence.

Subjects with older age had a higher and significant decrease in nicotine dependence after COVID-19 than their younger counterparts. Older subjects had a higher baseline FTND values and a higher duration of smoking. The higher decrease could have happened due to fear of severe disease among elderly subjects, higher probability of suffering from any comorbidity, and chances of having more severe symptoms, particularly respiratory symptoms. ${ }^{23}$ All these factors were independently related to reduction in nicotine dependence. Multiple previous studies on factors related to fear of COVID-19 have found older age to be significantly associated with fear of COVID-19..$^{24,25}$ Higher education was associated with less decrease in nicotine dependence. This finding should be interpreted in the context that most educated subjects were of younger age and had a milder disease.

The presence of symptomatic COVID-19, particularly respiratory symptoms, was also associated with a higher decrease in nicotine dependence. There is a common notion that smoking in itself causes multiple respiratory symptoms and added fear of COVID-19 could have been a trigger among study subjects to move toward lesser nicotine dependence. The authors could not find any previous studies which specifically estimated the effect of COVID-19 on nicotine dependence but the previous

\begin{tabular}{|c|c|c|c|c|c|c|c|}
\hline & Age & Smoking duration & FTND baseline & $\mathrm{SpO}_{2}$ baseline & $\mathrm{SpO}_{2}$ follow-up & PCFS baseline & $\begin{array}{c}\text { PCFS } \\
\text { follow-up }\end{array}$ \\
\hline $\begin{array}{l}\text { FTND } \\
\text { follow-up }\end{array}$ & -0.071 & -0.128 & 0.0175 & $0.194^{*}$ & $0.363^{*}$ & $-0.492^{*}$ & $-0.507^{\star}$ \\
\hline
\end{tabular}




\begin{tabular}{|c|c|c|c|c|c|c|}
\hline Variable & Subgroup & $\mathbf{N}$ & FTND Baseline & FTND follow-up & $\%$ change in FTND & $P$ value \\
\hline \multirow[t]{3}{*}{ Age group (years) } & $<35$ years & 45 & $5 \pm 0.32$ & $3.4 \pm 0.15$ & $16.6 \pm 6.08$ & $>0.00$ \\
\hline & $36-49$ years & 54 & $6 \pm 0.16$ & $4.3 \pm 0.2$ & $23.25 \pm 4.3$ & \\
\hline & $>50$ & 72 & $7 \pm 0.06$ & $3.5 \pm 0.21$ & $50.07 \pm 2.9$ & \\
\hline \multirow{3}{*}{ Education } & Uneducated & 27 & $7 \pm 0.12$ & $3.33 \pm 0.4$ & $52.38 \pm 6.9$ & $>0.006$ \\
\hline & Primary & 81 & $6.44 \pm 0.1$ & $4.11 \pm 0.1$ & $28.90 \pm 3.4$ & \\
\hline & Above primary & 63 & $5.43 \pm 0.1$ & $3.42 \pm 0.1$ & $29.45 \pm 4.6$ & \\
\hline \multirow[t]{3}{*}{ Socioeconomic status } & Low & 45 & $5.4 \pm 0.28$ & $4.4 \pm 0.15$ & $6.95 \pm 5.4$ & 0.001 \\
\hline & Middle & 81 & $6.44 \pm 0.1$ & $3.66 \pm 0.2$ & $41.01 \pm 3.5$ & \\
\hline & High & 45 & $6.42 \pm 0.2$ & $3.2 \pm 0.11$ & $43.93 \pm 3.7$ & \\
\hline \multirow[t]{2}{*}{ Marital status } & Single & 45 & $5 \pm 0.31$ & $2.6 \pm 0.25$ & $29.04 \pm 7.8$ & 0.4 \\
\hline & Married & 126 & $6.57 \pm 0.0$ & $4.14 \pm 0.1$ & $34.16 \pm 2.3$ & \\
\hline \multirow[t]{2}{*}{ Hypertension/diabetes } & Yes & 54 & $6.66 \pm 0.1$ & $3.33 \pm 0.2$ & $46.13 \pm 4.2$ & 0.0006 \\
\hline & No & 117 & $5.92 \pm 0.1$ & $3.92 \pm 0.1$ & $26.66 \pm 3.2$ & \\
\hline \multirow{2}{*}{ Chronic respiratory disease } & Yes & 4 & $5.65 \pm 0.0$ & $2.52 \pm 0.4$ & $42.57 \pm 3.1$ & 0.062 \\
\hline & No & 167 & $6.62 \pm 0.1$ & $4.54 \pm 0.0$ & $31.62 \pm 2.4$ & \\
\hline \multirow[t]{2}{*}{ Cigarette use at home } & Yes & 72 & $6.75 \pm 0.0$ & $4 \pm 0.24$ & $38.57 \pm 4.1$ & 0.066 \\
\hline & No & 99 & $5.72 \pm 0.1$ & $3.54 \pm 0.0$ & $28.62 \pm 3.4$ & \\
\hline \multirow[t]{2}{*}{ Symptoms } & Yes & 72 & $6.5 \pm 0.1$ & $2.6 \pm 0.14$ & $55.43 \pm 3.1$ & 0.0001 \\
\hline & No & 99 & $5.9 \pm 0.1$ & $4.54 \pm 0.1$ & $16.36 \pm 3.0$ & \\
\hline \multirow[t]{2}{*}{ Respiratory symptoms } & Yes & 63 & $7 \pm 0.07$ & $2.57 \pm 0.1$ & $63.35 \pm 2.3$ & $>0.00$ \\
\hline & No & 108 & $5.66 \pm 0.1$ & $4.42 \pm 0.1$ & $15 \pm 2.87$ & \\
\hline \multirow[t]{2}{*}{ Supplementary oxygen } & Yes & 18 & $6.5 \pm 0.1$ & $2 \pm 0.24$ & $83.33 \pm 4.0$ & $>0.00$ \\
\hline & No & 153 & $6.12 \pm 0.1$ & $3.4 \pm 0.1$ & $26.86 \pm 2.5$ & \\
\hline
\end{tabular}

Percent change in FTND treated as dependent variable. Paired t-test used for variables with two subgroups and ANOVA for those with more than 2 subgroups. FTND: Fagerstrom Test for Nicotine Dependence

\begin{tabular}{|c|c|c|c|c|c|}
\hline & Coef. & Std. error & $\mathbf{t}$ & $95 \%$ conf. interval & $P$ value \\
\hline Married versus single & -56.45 & 7.011 & -8.05 & $-70.30--42.60$ & 0.000 \\
\hline Older age & -3.212 & 0.450 & -7.13 & $-4.10--2.32$ & 0.000 \\
\hline Smoking duration & 0.886 & 0.657 & 1.35 & $-0.413-2.18$ & 0.180 \\
\hline $\mathrm{SpO}_{2}$ baseline & -0.0575 & 2.11 & -0.03 & $-4.23-4.11$ & 0.978 \\
\hline PCFS baseline & -6.68 & 3.54 & -1.88 & $-13.69-0.33$ & 0.062 \\
\hline PCFS follow-up & 3.878 & 2.93 & 1.32 & $-1.91-9.66$ & 0.188 \\
\hline Education primary & -4.68 & 5.82 & -0.80 & $-16.18-6.81$ & 0.422 \\
\hline Education secondary & 10.09 & 4.91 & 2.06 & $0.39-19.79$ & 0.042 \\
\hline SES lower & -39.48 & 7.23 & -5.46 & $-53.77--25.18$ & 0.000 \\
\hline SES middle & -18.20 & 8.66 & -2.10 & $-35.32--1.08$ & 0.037 \\
\hline Comorbidity yes & -11.90 & 4.47 & -2.66 & $-20.74--3.06$ & 0.009 \\
\hline Symptoms yes & 13.71 & 14.85 & 0.92 & $-15.61-43.05$ & 0.357 \\
\hline Supplementary $\mathrm{O}_{2}$ & -58.60 & 19.14 & -3.06 & $-96.41--20.79$ & 0.003 \\
\hline
\end{tabular}

studies have found decreased smoking after any acute health condition and after any natural disasters. ${ }^{26,27}$

Symptomatic COVID-19 patients and those who required supplementary oxygen may have developed decreased dependence on account of symptoms and fall in $\mathrm{SpO}_{2}$. Persistence of smoking during any respiratory illness is associated with increase in symptoms which may hold true for COVID-19 also. ${ }^{26}$ Even cessation for a short term is usually associated with immediate improvement in respiratory symptoms in other respiratory illness which may explain the significant difference between symptomatic and asymptomatic subjects. ${ }^{28}$ All subjects diagnosed positive for COVID-19 were provided with a pulse oximeter as part of national management protocol. As the subjects could now monitor their SpO2 levels and since smoking tends to decrease blood oxygen levels, the decrease in nicotine dependence could have been partly contributed by providing subjects with pulse oximeter. This could be a potential confounding factor as decrease could have been partly due to regular monitoring of $\mathrm{SpO}_{2}$ after the diagnosis of COVID-19. Being married was also 
significantly associated with a higher decrease in FTND score which can be due to higher degree of family support and counseling for smoking cessation.

Functional assessment was done using Post-COVID-19 Functional Scale (PCFS) at baseline (immediately after the diagnosis) and at follow-up visit. ${ }^{21}$ There was no significant difference from the initial to follow-up in PCFS. COVID-19 is associated with a decrease in functional status which depends on severity of illness in addition to other factors. Our study did not estimate any change which may be due to the fact that the baseline was done after the diagnosis and not before that and around $40 \%$ subjects were symptomatic at that time. Hence, the PCFS assessment at baseline cannot be considered to be a true baseline value. The decrease was not significantly associated with PCFS scores during the initial or follow-up visit.

The study recruited only males on account of the high prevalence of smoking in males with around $1 / 3$ of males using smoking forms of tobacco in the general population. Although the initial plan was to include both genders in the study, on pre-testing, no female COVID-19 patient reported as being current smoker. A previous adult tobacco survey in the area had estimated the prevalence of smoking to be $33 \%$ in males and $5 \%$ in females. ${ }^{29}$ In addition, there was a higher chance of underreporting of smoking in females due to higher taboos regarding female smoking in the region.

Our study had some limitations, first, the baseline FTND test was done immediately after diagnosis of COVID-19 that may have already impacted the subject's attitude toward smoking, so cannot be taken as a true baseline value. On the other hand, this study sheds light on the change that happened from the $1^{\text {st }}$ day of COVID-19 diagnosis to early recovery phase, which holds its own importance. The study also did not have a comparable group, so it is difficult to comment whether this decrease is specific to COVID-19 or any disease would have the same impact. Given the short observation time, our ability to estimate long-term changes on nicotine dependence is limited. Further follow-ups can shed light on that.

\section{Limitations of the study}

Given the cross-sectional nature of the study, it was not possible to study the temporality of association. In addition, the baseline reading was taken after COVID-19 diagnosis as there are chances that the subjects develop aversion to cigarettes immediately after diagnosis. Still the authors had no option as there are no estimates of FTND test available for the general population. Still the change after the diagnosis can shed light on change in cigarette dependence after diagnosis.

\section{CONCLUSION}

While tobacco smoking is associated with adverse outcomes from COVID-19, the decrease in nicotine dependence seen after COVID-19 in this study should be used as an opportunity to include interventions related to smoking cessation during follow-up of COVID-19 patients. Effective behavior change communication strategy is the need of the hour to ensure that the shift from pre-contemplation to contemplation is maintained leading to smoking cessation.

\section{ACKNOWLEDGMENT}

The authors would like to thank the doctors and staff who were involved in treatment of patients and also the subjects for their consent to participate in this study.

\section{REFERENCES}

1. Wu F, Guo Y, Chatterji S, Zheng $Y$, Naidoo N, Jiang $Y$, et al. Common risk factors for chronic non-communicable diseases among older adults in China, Ghana, Mexico, India, Russia and South Africa: The study on global AGEing and adult health (SAGE) wave 1. BMC Public Health. 2015;15(1):88.

https://doi.org/10.1186/s12889-015-1407-0

2. Yang JJ, Yu D, Wen W, Shu XO, Saito E, Rahman S, et al. Tobacco Smoking and Mortality in Asia: A Pooled Meta-analysis. JAMA Netw Open. 2019;2(3):e191474-e191474.

3. World Health Organization. Tobacco. WHO Website. Geneva: World Health Organization; 2021. Available from: https://www.who.int/news-room/fact-sheets/detail/tobacco [Last accessed on 2021 Aug 27].

4. Bennett JE, Stevens GA, Mathers CD, Bonita R, Rehm J, Kruk ME, et al. NCD Countdown 2030: Worldwide trends in non-communicable disease mortality and progress towards sustainable development goal target 3.4. Lancet. 2018;392(10152):1072-1088.

https://doi.org/10.1016/s0140-6736(18)31992-5

5. World Health Organization. WHO Report on the Global Tobacco Epidemic, 2017: Monitoring Tobacco Use and Prevention Policies. Geneva: World Health Organization; 2017. Available from: https://apps.who.int/iris/handle/10665/255874. [Last accessed on 2021 Aug 29].

6. Chatterjee K, Chatterjee K, Kumar A and Shankar S. Healthcare impact of COVID-19 epidemic in India: A stochastic mathematical model. Med J Armed Forces India. 2020;76(2):147-155.

https://doi.org/10.1016/j.mjafi.2020.03.022

7. Frawley $T$, van Gelderen $F$, Somanadhan S, Coveney K, Phelan A, Lynam-Loane P, et al. The impact of COVID-19 on health systems, mental health and the potential for nursing. Ir $\mathrm{J}$ Psychol Med. 2021;38(3):220-226.

https://doi.org/10.1017/ipm.2020.105

8. Sokolovsky AW, Hertel AW, Micalizzi L, White HR and Hayes KJ. Preliminary impact of the COVID-19 pandemic on smoking and vaping in college students. Addict Behav. 2021;115:106783. https://doi.org/10.1016/j.addbeh.2020.106783

9. Singh B and Jain $S$ and Rastogi $A$. Effects of nationwide COVID-19 lockdown on lifestyle and diet: An Indian survey. 
J Fam Med Prim Care. 2021;10(3):1246-1250.

https://doi.org/10.4103/jfmpc.jfmpc_2046_20

10. Vardavascorresponding $\mathrm{Cl}$, Nikitara K. COVID-19 and smoking: A systematic review of the evidence. Tob Induc Dis. 2020;18:20. https://doi.org/10.18332/tid/119324

11. Reddy RK, Charles WN, Sklavounos A, Dutt A, Seed PT and Khajuria A. The effect of smoking on COVID-19 severity: A systematic review and meta-analysis. J Med Virol. 2021;93(2):1045-1056. https://doi.org/10.1002/jmv.26389

12. Klok FA, Boon GJ, Barco S, Endres M, Geelhoed JJ, Knauss S, et al. The post-COVID-19 functional status scale: A tool to measure functional status over time after COVID-19. Eur Respir J. 2020;56(1):2001494

https://doi.org/10.1183/13993003.01494-2020

13. Weber CF, Hatschbach P, Pithan SA and dos Dullius AIS Measure nicotine dependence by the fagerström test for nicotine dependence. Rev Gaúcha Odontol. 2017;65(3):208-215. https://doi.org/10.1590/1981-863720170002000043223

14. van Amsterdam J, Vorspan F, Snijder MB, van den Brink W, Schene AH, Stronks $\mathrm{K}$, et al. Use of the Fagerström test to assess differences in the degree of nicotine dependence in smokers from five ethnic groups: The HELIUS study. Drug Alcohol Depend. 2019;194:197-204.

https://doi.org/10.1016/j.drugalcdep.2018.10.011

15. MOHFW. Coronavirus Outbreak in Jammu and Kashmir. MOHFW; 2021. Available from: https://www.covid19india.org/ state/JK [Last accessed on 2021 Aug 28].

16. World Health Organization. India: WHO Coronavirus Disease (COVID-19) Dashboard With Vaccination Data WHO Coronavirus (COVID-19) Dashboard with Vaccination Data. WHO Website. Geneva: World Health Organization; 2021. Available from: https://covid19.who.int/region/searo/country/in [Last accessed on 2021 Aug 28]. https://doi.org/10.46945/bpj.10.1.03.01

17. National Tobacco Control Programme. Global Adult Tobacco Survey Second Round, India 2016-17; 2017. Available from: https://ntcp.nhp.gov.in/surveys_reports_publications [Last accessed on 2021 Aug 28]

18. Center for Disease Control. NHIS Adult Tobacco Use Glossary. National Center for Health Statistics; 2017. Available from: https://www.cdc.gov/nchs/nhis/tobacco/tobacco_glossary.htm [Last accessed on 2021 Sep 18]

19. Indian Council of Medical Research. Testing Strategy for India ICMR Website; 2021. Available from: https://www.icmr.gov.in/ cteststrat.html [Last accessed on 2021 Aug 28]

20. Iqbal A, Iqbal K, Ali SA, Azim D, Farid E, Baig MD, et al. The
COVID-19 sequelae: A cross-sectional evaluation of postrecovery symptoms and the need for rehabilitation of COVID-19 survivors. Cureus. 2021;13(2):e13080.

https://doi.org/10.7759/cureus. 13080

21. Taboada M, Cariñena A, Moreno E, Rodríguez N, Domínguez MJ, Casal A, et al. Post-COVID-19 functional status six-months after hospitalization. J Infect. 2021;82(4):e31. https://doi.org/10.1016/j.jinf.2020.12.022

22. Landi F, Gremese E, Bernabei R, Fantoni M, Gasbarrini A, Settanni CR, et al. Post-COVID-19 global health strategies: The need for an interdisciplinary approach. Aging Clin Exp Res. 2020;32(8):1613-20.

23. Rodríguez-Hidalgo AJ, Pantaleón Y, Dios I and Falla D. Fear of COVID-19, stress, and anxiety in university undergraduate students: A predictive model for depression. Front Psychol. 2020;32(8):3041.

https://doi.org/10.3389/fpsyg.2020.591797

24. Yadav UN, Yadav OP, Singh DR, Ghimire S, Rayamajhee B, Mistry SK, et al. Perceived fear of COVID-19 and its associated factors among Nepalese older adults in eastern Nepal: A crosssectional study. PLoS One. 2021;16(7):e0254825. https://doi.org/10.1371/journal.pone.0254825

25. Mistry SK, Ali AR, Akther F, Yadav UN and Harris MF. Exploring fear of COVID-19 and its correlates among older adults in Bangladesh. Glob Health. 2021;17(1):47. https://doi.org/10.1186/s12992-021-00698-0

26. Greenhalgh T, Knight M, A'Court C, Buxton M, Husain L. Management of post-acute covid-19 in primary care. BMJ. 2020;370:m3026. https://doi.org/10.1136/bmj.m3026

27. Nakano H, Ohira T, Maeda M, Yabe H, Ohtsuru A, Suzuki Y, et al. Associations of disaster-related and psychosocial factors with changes in smoking status after a disaster: A cross-sectional survey after the Great East Japan Earthquake. BMJ Open. 2018;8(6):e018943.

https://doi.org/10.1136/bmjopen-2017-018943

28. Alqahtani JS, Oyelade T, Aldhahir AM, Alghamdi SM, Almehmadi M, Alqahtani AS, et al. Prevalence, severity and mortality associated with COPD and smoking in patients with COVID-19: A rapid systematic review and meta-analysis. PLoS One. 2020;15(5):e0233147. https://doi.org/10.1371/journal.pone.0233147

29. Tata Institute of Social Sciences. Global Adult Tobacco Survey 2, Factsheet J\&K. New Delhi; 2017. Available from: http:// chrome-extension://efaidnbmnnnibpcajpcglclefindmkaj/ viewer.html?pdfurl=https $\% 3 \mathrm{~A} \% 2 \mathrm{~F} \% 2 \mathrm{Ftiss}$. edu\%2Fuploads $\% 2$ Ffiles $\% 2 F 01$ JK.pdf and clen $=1746370$

\section{Authors' Contributions:}

AJ-was involved in conceptualizing, data analysis, and writing of the manuscript; HR-was involved in designing study protocols, data collection, collation and analysis, and provided inputs to the manuscript; SSL-was involved in developing study protocols data analysis and manuscript writing.

Work attributed to:

Department of Community Medicine, Government Medical College, Srinagar - 190 010, India.

ORCID ID:

Dr. Hilal Rather- (D) https://orcid.org/0000-0001-5408-1174

Dr. Shafat Sideeq Lone- (1) https://orcid.org/0000-0002-6499-7247

Dr. Asif Jeelani- (D https://orcid.org/0000-0001-9092-9320

Source of Funding: None, Conflicts of Interest: None. 